\title{
The Epidemiology of Revision Total Knee Arthroplasty in the United States
}

\author{
Kevin J. Bozic MD, MBA, Steven M. Kurtz PhD, Edmund Lau MS, \\ Kevin Ong PhD, Vanessa Chiu MPH, Thomas P. Vail MD, Harry E. Rubash MD, \\ Daniel J. Berry MD
}

Published online: 25 June 2009

(C) The Author(s) 2009. This article is published with open access at Springerlink.com

\begin{abstract}
Understanding the cause of failure and type of revision total knee arthroplasty (TKA) procedures performed in the United States is essential in guiding research, implant design, and clinical decision making in TKA. We assessed the causes of failure and specific types of revision TKA procedures performed in the United States using newly implemented ICD-9-CM diagnosis and procedure codes related to revision TKA data from the Nationwide Inpatient Sample (NIS) database. Clinical, demographic, and economic data were reviewed and analyzed from 60,355 revision TKA procedures performed in the United States between October 1, 2005 and December 31, 2006. The most common causes of revision TKA were infection (25.2\%) and implant loosening (16.1\%), and the most common type of revision TKA procedure reported was all component revision (35.2\%). Revision TKA procedures
\end{abstract}

One of more of the authors (KJB) received financial support from the Orthopaedic Research and Education Foundation. One or more of the authors (SMK, KO, EL) are employees of Exponent, Inc. One or more of the authors (DJB, TPV) receive consulting income and royalties from DePuy, Inc. One author (HER) receives royalties from Zimmer, Inc.

This work was performed at the University of California,

San Francisco and Exponent, Inc.

\section{K. J. Bozic ( $\square)$, V. Chiu}

Department of Orthopaedic Surgery and Philip R.

Lee Institute for Health Policy Studies, University of California,

San Francisco, 500 Parnassus Ave., MU320W, San Francisco,

CA 94143-0728, USA

e-mail: bozick@orthosurg.ucsf.edu

S. M. Kurtz, K. Ong

Exponent, Inc., Philadelphia, PA, USA

E. Lau

Exponent, Inc., Menlo Park, CA, USA were most commonly performed in large, urban, nonteaching hospitals in Medicare patients ages 65 to 74 . The average length of hospital stay (LOS) for all revision TKA procedures was 5.1 days, and the average total charges were $\$ 49,360$. However, average LOS, average charges, and procedure frequencies varied considerably by census region, hospital type, and procedure performed.

Level of Evidence: Level II, economic and decision analysis. See Guidelines for Authors for a complete description of levels of evidence.

\section{Introduction}

Total knee arthroplasty (TKA) is a clinically efficacious and cost-effective intervention, with high rates of success in terms of alleviating pain and improving function in patients with advanced arthritis of the knee [2, 11, 12, 21, 22, 25]. However, there has been a steady rise in the volume of revision TKA procedures in the United States in recent years. The increase in revision TKA procedures is related to a number of factors, including an increase in primary TKA procedure volumes, factors related to modifications in surgical technique, patient selection, implant longevity, and an

\section{T. P. Vail}

Department of Orthopaedic Surgery, University of California, San Francisco, 500 Parnassus Ave., MU320W, San Francisco, CA 94143-0728, USA

H. E. Rubash

Department of Orthopaedic Surgery, Massachusetts General Hospital, Boston, MA, USA

D. J. Berry

Department of Orthopaedic Surgery, Mayo Clinic, Rochester, MN, USA 
Table 1. ICD-9-CM diagnosis and procedure codes related to revision TKA, introduced on October 1, 2005

\begin{tabular}{l}
\hline Code $\quad$ Description \\
\hline Diagnosis codes \\
996.41 Mechanical loosening of prosthetic joint \\
996.42 Dislocation of prosthetic joint \\
996.43 Prosthetic joint implant failure/breakage \\
996.44 Periprosthetic fracture around prosthetic joint \\
996.45 Periprosthetic osteolysis \\
996.46 Articular bearing surface wear of a prosthetic joint \\
996.47 Other mechanical complication of prosthetic joint implant \\
996.49 Other mechanical complication of other internal orthopedic \\
Procedure codes \\
$00.80 \quad$ Revision of tibial, patellar, and femoral components \\
00.81 Revision of tibial component \\
00.82 Revision of femoral component \\
00.83 Revision of patellar component \\
00.84 Isolated revision of tibial insert \\
$80.06 \quad$ Arthrotomy/removal of prosthesis \\
$81.55 \quad$ Revision of knee, NOS
\end{tabular}

expansion of the indications to include younger, more active patients [16, 23]. Furthermore, recent estimates suggest the number of revision TKA procedures is expected to increase substantially over the next several decades [14].

Most of the information published regarding the causes of failure and indications for revision TKA in the United States comes from single-surgeon or single-center case series, or multicenter cohort studies from large, academic institutions [5, 6, 10, 19, 26, 28]. Limited information currently exists regarding TKA failure among the larger population of patients who undergo TKA at smaller, community-based hospitals. Furthermore, due to the limitations and lack of specificity associated with administrative codes related to revision TKA that existed until very recently, previous investigators who attempted to characterize the epidemiology of revision TKA using large administrative databases were unable to provide insight into the specific causes of failure or types of revision TKA procedures performed $[9,15]$.

In 2005, a group of researchers from the American Academy of Orthopaedic Surgeons and the American Association of Hip and Knee Surgeons worked with officials from the Center for Medicare and Medicaid Services (CMS) and the National Center for Health Statistics (NCHS) to request a series of changes to the ICD-9-CM diagnosis and procedure codes related to failed total joint arthroplasties (TJA) and revision TJA procedures [4]. The primary objective of the requested coding changes was to provide more accurate and clinically descriptive administrative codes regarding the cause of TJA failures that could be used for tracking clinical outcomes, and thereby facilitate feedback to surgeons, hospitals, and medical device companies. Recognizing the potential public health benefits of having better information regarding the cause of failure and type of revision TJA procedure performed, CMS and the NCHS implemented the requested changes in October 2005 (Table 1) [4]. As a result of these administrative coding changes, it is now possible for the first time to use large administrative claims databases to gather more detailed information on the cause of failure and type of revision TKA procedure performed in a nationally representative population.

The objectives of this study were to: (1) identify the indications for revision TKA; (2) determine revision TKA procedure frequencies; (3) evaluate adoption and usage of the newly adopted ICD-9-CM diagnosis and procedure codes related to revision TKA; (4) assess age, gender, race, payor type and US Census Region of revision TKA patients; and (5) ascertain length of stay and total charge by type of revision TKA procedure.

\section{Materials and Methods}

We used the Nationwide Inpatient Sample (NIS) to identify revision TKA procedures performed in the United States between October 1, 2005 and December 31, 2006 using the 9th Revision of the International Classification of Diseases (ICD-9-CM) procedure codes 00.80 (all component revision), 00.81 (tibial component revision), 00.82 (femoral component revision), 00.83 (patellar component revision), 00.84 (isolated tibial insert exchange), 80.06 (arthrotomy/ removal of prosthesis), and 81.55 (revision TKA, not otherwise specified). The NIS is a stratified, statistically valid survey of hospitals conducted by the Federal Healthcare Cost and Utilization Project. Hospitals within the sampling frame are stratified according to census regions, ownership (eg, public, private), location (rural, urban), teaching status, and bed size. Hospitals are randomly selected to achieve an approximate $20 \%$ sample of the universe of hospitals in each stratum. All discharge records from each of the selected hospitals are collected and form part of the NIS file for a given year. In 2006, the NIS had a sample size of approximately 8 million records from 1045 hospitals in 38 states, which represents approximately $20 \%$ of all discharges from hospitals in the United States, regardless of payment source. Because of the large size of the database, the NIS is particularly wellsuited for epidemiological studies related to specific procedures or diseases in the national population. The total sample size included in the analysis was 60,355 revision TKA procedures with a mean patient age of 65.8 years. 
Men comprised $42.6 \%$ of the sample, and $83.3 \%$ of the patients were white.

The prevalence of revision TKA procedures was calculated using the NIS for population subgroups in the United States stratified by age, gender, race, diagnosis, census region, primary payor class, and hospital characteristics (size, location [9], and teaching status). Cause of failure, average length of hospital stay, and total charges were also computed for each type of revision TKA procedure.

\section{Results}

The most common causes of revision TKA (Table 2) were infection (25.2\%), mechanical loosening (16.1\%), and implant failure/breakage (9.7\%). Infection was the most common indication for arthrotomy/removal of prosthesis (79.1\%). Mechanical loosening was the most common reason for all component revision, tibial component revision, femoral component revision, and patellar component revision. Infection was the most common indication for isolated tibial insert revision. Overall, $76.5 \%$ of all TKA revisions were coded either using one of the newly implemented ICD-9 diagnosis codes $(53.3 \%)$ or with the code for infection of an internal joint prosthesis $(25.2 \%)$. In addition, $8.7 \%$ of all revisions were coded as "other mechanical complication of a prosthetic joint implant" (996.47), and 6.7\% were coded as "other mechanical complication of other internal orthopaedic device, implant, or graft" (996.49).

Overall, $91 \%$ of all revision TKA procedures during the time period under study were coded using at least one of the newly implemented ICD-9 procedure codes (00.80 to 00.84) or the arthrotomy/removal of prosthesis procedure code (80.06) (Table 3). The most common type of revision TKA procedure reported during the time period under study was all component revision (35.2\%), followed by

Table 2. Diagnosis codes associated with revision TKA procedures

\begin{tabular}{|c|c|c|c|c|c|c|c|c|}
\hline Diagnosis codes & $\begin{array}{l}\text { Total, all } \\
\text { revisions }\end{array}$ & $\begin{array}{l}00.80 \text { All } \\
\text { component } \\
\text { revision }\end{array}$ & $\begin{array}{l}00.81 \text { Tibial } \\
\text { component } \\
\text { revision }\end{array}$ & $\begin{array}{l}00.82 \\
\text { Femoral } \\
\text { component } \\
\text { revision }\end{array}$ & $\begin{array}{l}00.83 \\
\text { Patellar } \\
\text { component } \\
\text { revision }\end{array}$ & $\begin{array}{l}00.84 \\
\text { Isolated } \\
\text { tibial insert } \\
\text { revision }\end{array}$ & $\begin{array}{l}80.06 \\
\text { Arthrotomy } \\
\text { removal of } \\
\text { prosthesis }\end{array}$ & $\begin{array}{l}81.55 \text { Knee } \\
\text { revision, } \\
\text { NOS }\end{array}$ \\
\hline $\begin{array}{l}\text { Number of } \\
\text { Revisions }\end{array}$ & 60,436 & 21,285 & 5774 & 2436 & 3122 & 5483 & 9202 & 5678 \\
\hline $\begin{array}{l}996.41 \\
\text { Mechanical } \\
\text { loosening }\end{array}$ & $9711(16.1 \%)$ & $4072(19.1 \%)$ & $1421(24.6 \%)$ & $562(23.1 \%)$ & $430(13.8 \%)$ & $270(4.9 \%)$ & $427(4.6 \%)$ & $730(12.8 \%)$ \\
\hline $\begin{array}{l}996.42 \\
\text { Dislocation }\end{array}$ & $4268(7.1 \%)$ & $1459(6.9 \%)$ & $472(8.2 \%)$ & $262(10.8 \%)$ & $380(12.2 \%)$ & $526(9.6 \%)$ & $176(1.9 \%)$ & $397(7.0 \%)$ \\
\hline $\begin{array}{l}996.43 \text { Implant } \\
\text { failure/breakage }\end{array}$ & $5852(9.7 \%)$ & $2542(11.9 \%)$ & $648(11.2 \%)$ & $246(10.1 \%)$ & $396(12.7 \%)$ & $437(8.0 \%)$ & $158(1.7 \%)$ & $539(9.5 \%)$ \\
\hline $\begin{array}{l}996.44 \\
\quad \text { Periprosthetic } \\
\text { fracture }\end{array}$ & $900(1.5 \%)$ & $309(1.5 \%)$ & $121(2.1 \%)$ & $78(3.2 \%)$ & $33(1.1 \%)$ & $14(0.3 \%)$ & $64(0.7 \%)$ & $77(1.4 \%)$ \\
\hline $\begin{array}{l}996.45 \\
\quad \begin{array}{l}\text { Periprosthetic } \\
\text { osteolysis }\end{array}\end{array}$ & $1910(3.2 \%)$ & $919(4.3 \%)$ & $140(2.4 \%)$ & $111(4.5 \%)$ & $30(1.0 \%)$ & $174(3.2 \%)$ & $80(0.9 \%)$ & $64(1.1 \%)$ \\
\hline $\begin{array}{r}996.46 \text { Bearing } \\
\text { surface wear }\end{array}$ & $2967(4.9 \%)$ & $917(4.3 \%)$ & $419(7.3 \%)$ & $43(1.8 \%)$ & $195(6.2 \%)$ & $630(11.5 \%)$ & $15(0.2 \%)$ & $170(3.0 \%)$ \\
\hline $\begin{array}{l}996.47 \text { Other } \\
\text { mechanical } \\
\text { complication of } \\
\text { prosthetic joint } \\
\text { implant }\end{array}$ & $5247(8.7 \%)$ & $2148(10.1 \%)$ & $634(11.0 \%)$ & $316(13.0 \%)$ & $389(12.5 \%)$ & $405(7.4 \%)$ & $122(1.3 \%)$ & $529(9.3 \%)$ \\
\hline $\begin{array}{l}996.49 \text { Other } \\
\text { mechanical } \\
\text { complication of } \\
\text { other internal } \\
\text { orthopedic } \\
\text { device implant } \\
\text { or graft }\end{array}$ & $4040(6.7 \%)$ & $1722(8.1 \%)$ & $492(8.5 \%)$ & $171(7.0 \%)$ & $277(8.9 \%)$ & $217(4.0 \%)$ & $202(2.2 \%)$ & $410(7.2 \%)$ \\
\hline 996.66 Infection & $15,233(25.2 \%)$ & $2902(13.6 \%)$ & $657(11.4 \%)$ & $236(9.7 \%)$ & $173(5.5 \%)$ & $1710(31.2 \%)$ & $7281(79.1 \%)$ & $1107(19.5 \%)$ \\
\hline
\end{tabular}

Note: Multiple diagnosis codes allowed. 
Table 3. Revision TKA procedure frequencies by primary payor class

\begin{tabular}{lcccrr}
\hline Procedure & \multicolumn{2}{l}{ Primary payor class } & & & \\
\cline { 2 - 5 } & Medicare & Medicaid & Private & Other & All \\
\hline 00.80 All component revision & $12,665(21.0 \%)$ & $573(0.9 \%)$ & $6776(11.2 \%)$ & $1252(2.1 \%)$ & $21,267(35.2 \%)$ \\
00.81 Tibial component revision & $3275(5.4 \%)$ & $201(0.3 \%)$ & $1966(3.3 \%)$ & $320(0.5 \%)$ & $5762(9.5 \%)$ \\
00.82 Femoral component revision & $1317(2.2 \%)$ & $107(0.2 \%)$ & $810(1.3 \%)$ & $197(0.3 \%)$ & $2431(4.0 \%)$ \\
00.83 Patellar component revision & $2020(3.3 \%)$ & $124(0.2 \%)$ & $823(1.4 \%)$ & $155(0.3 \%)$ & $3122(5.2 \%)$ \\
00.84 Isolated tibial insert exchange & $3216(5.3 \%)$ & $243(0.4 \%)$ & $1669(2.8 \%)$ & $349(0.6 \%)$ & $5478(9.1 \%)$ \\
80.06 Arthrotomy/removal of prosthesis & $5629(9.3 \%)$ & $411(0.7 \%)$ & $2622(4.3 \%)$ & $530(0.9 \%)$ & $9191(15.2 \%)$ \\
81.55 Knee revision NOS & $3198(5.3 \%)$ & $209(0.3 \%)$ & $1884(3.1 \%)$ & $377(0.6 \%)$ & $5668(9.4 \%)$ \\
Other combinations & $4604(7.6 \%)$ & $251(0.4 \%)$ & $2150(3.6 \%)$ & $452(0.7 \%)$ & $7451(12.3 \%)$ \\
Total & $35,924(59.5 \%)$ & $2119(3.5 \%)$ & $18,700(30.9 \%)$ & $3632(6.0 \%)$ & $60,375(100.0 \%)$ \\
\hline
\end{tabular}

Table 4. Revision TKA procedure demographics by U.S. census region

\begin{tabular}{lccccc}
\hline Procedure & U.S. census region & & & \\
\cline { 2 - 5 } & Northeast & Midwest & South & West & Total \\
\hline 00.80 All component revision & $3298(5.5 \%)$ & $6079(10.1 \%)$ & $7785(12.9 \%)$ & $4123(6.8 \%)$ & $21,285(35.2 \%)$ \\
00.81 Tibial component revision & $804(1.3 \%)$ & $1648(2.7 \%)$ & $2174(3.6 \%)$ & $1149(1.9 \%)$ & $5774(9.6 \%)$ \\
00.82 Femoral component revision & $311(0.5 \%)$ & $660(1.1 \%)$ & $1008(1.7 \%)$ & $457(0.8 \%)$ & $2436(4.0 \%)$ \\
00.83 Patellar component revision & $541(0.9 \%)$ & $788(1.3 \%)$ & $1261(2.1 \%)$ & $532(0.9 \%)$ & $3122(5.2 \%)$ \\
00.84 Isolated tibial insert exchange & $911(1.5 \%)$ & $1394(2.3 \%)$ & $1969(3.3 \%)$ & $1209(2.0 \%)$ & $5483(9.1 \%)$ \\
80.06 Arthrotomy/removal of prosthesis & $1560(2.6 \%)$ & $2370(3.9 \%)$ & $3576(5.9 \%)$ & $1695(2.8 \%)$ & $9202(15.2 \%)$ \\
81.55 Knee revision, NOS & $1166(1.9 \%)$ & $1474(2.4 \%)$ & $2309(3.8 \%)$ & $729(1.2 \%)$ & $5678(9.4 \%)$ \\
Other combinations & $567(0.9 \%)$ & $665(1.1 \%)$ & $1000(1.7 \%)$ & $615(1.0 \%)$ & $2847(4.7 \%)$ \\
Total & $9836(16.3 \%)$ & $16,509(27.3 \%)$ & $22,681(37.5 \%)$ & $11,410(18.9 \%)$ & $60,436(100.0 \%)$ \\
\hline
\end{tabular}

Northeast $=$ Connecticut, Maine, Massachusetts, New Hampshire, Rhode Island, Vermont, New Jersey, New York, Pennsylvania. Midwest = Indiana, Illinois, Michigan, Ohio, Wisconsin, Iowa, Nebraska, Kansas, North Dakota, Minnesota, South Dakota, Missouri. South = Delaware, District of Columbia, Florida, Georgia, Maryland, North Carolina, South Carolina, Virginia, West Virginia, Alabama, Kentucky, Mississippi, Tennessee, Arkansas, Louisiana, Oklahoma, Texas. West = Arizona, Colorado, Idaho, New Mexico, Montana, Utah, Nevada, Wyoming, Alaska, California, Hawaii, Oregon, Washington.

arthrotomy/removal of prosthesis (15.2\%) and tibial component revision (9.5\%). All component revisions, patellar component revisions, and isolated tibial component revisions were most commonly reported in the 65- to 74-yearold age group $(30.2 \%, 33.9 \%$, and $29 \%$, respectively), while femoral component revisions were more commonly reported in patients age 55 to 64 (28.8\%). Revision TKA procedures were most commonly reported in urban nonteaching hospitals (48.8\%), compared with $41.2 \%$ in urban teaching hospitals, and only $9.9 \%$ in rural hospitals.

Large hospitals accounted for the highest percentage of revision TKA procedures $(61.3 \%$ ), while only $13.7 \%$ of revision TKAs were reported in small hospitals. Medicare was the primary payor for $59.5 \%$ of revision TKA procedures, whereas private insurance patients and Medicaid patients accounted for $31 \%$ and only $3.5 \%$ of cases, respectively. Geographically, the highest percentage of revision TKA procedures were reported in the South
(37.5\%), and the lowest percentage of revision procedures were reported in the Northeast (16.3\%) (Table 4). Average length of stay and total charges also differed by U.S. Census region. The shortest average length of stay (4.8 days) was reported in the Midwest and the West, compared with the longest average length of stay (5.8 days) in the Northeast. Average total charges for revision TKA procedures were highest in the West $(\$ 61,465)$, and were 1.4 times the average total charges for revision TKA procedures in the Midwest $(\$ 43,527)$.

The evaluation of resource utilization (Table 5) revealed the average hospital length of stay for all types of revision TKA procedures was 5.1 days; arthrotomy/removal of prosthesis procedures were associated with the longest length of stay (8.1 days) and patellar component revision were associated with the shortest length of stay (3.4 days). The average billed charges for all types of revision TKA procedures were $\$ 49,360$. All component revisions had the 
Table 5. Revision TKA procedure average length of stay (LOS) and average total hospital charges

\begin{tabular}{|c|c|c|c|c|c|c|}
\hline Procedure & Total & $\begin{array}{l}\text { Average age } \\
\text { (years) }\end{array}$ & $\begin{array}{l}\text { Gender } \\
\text { (\% female) }\end{array}$ & $\begin{array}{l}\text { Race } \\
\text { (\% white) }\end{array}$ & $\begin{array}{l}\text { Average LOS } \\
\text { (days) }\end{array}$ & $\begin{array}{l}\text { Average total } \\
\text { charge }\end{array}$ \\
\hline 00.80 All component revision & 21,285 & 66.0 & 57.2 & 83.3 & 4.5 & $\$ 56,087$ \\
\hline 00.81 Tibial component revision & 5774 & 65.1 & 63.6 & 84.0 & 4.2 & $\$ 36,193$ \\
\hline 00.82 Femoral component revision & 2436 & 63.4 & 57.2 & 81.6 & 4.7 & $\$ 51,261$ \\
\hline 00.83 Patellar component revision & 3122 & 67.0 & 58.1 & 85.2 & 3.4 & $\$ 26,047$ \\
\hline 00.84 Isolated tibial insert exchange & 5483 & 65.9 & 57.6 & 85.3 & 4.8 & $\$ 32,511$ \\
\hline 80.06 Arthrotomy/removal of prosthesis & 9202 & 65.6 & 51.3 & 83.0 & 8.1 & $\$ 54,229$ \\
\hline 81.55 Knee revision, NOS & 5678 & 65.7 & 58.7 & 78.8 & 4.7 & $\$ 48,208$ \\
\hline Other combinations & 7456 & 65.7 & 55.6 & 82.6 & 6.9 & $\$ 58,371$ \\
\hline Total & 60,436 & 65.8 & 57.4 & 83.3 & 5.1 & $\$ 49,360$ \\
\hline
\end{tabular}

Note: Demographic percentages, LOS, and charges computed from known values only.

highest average billed charges $(\$ 56,087)$, while patellar component revision procedures had the lowest average billed charges $(\$ 26,047)$.

\section{Discussion}

Despite the excellent functional outcomes and long-term implant survivorship that have been reported with primary TKA [2, 5, 28], TKA failure and revision TKA remain substantial clinical challenges for orthopaedic surgeons and their patients. Furthermore, despite continual changes in surgical technique and implant design, the revision TKA burden (eg, the percentage of revision TKA cases as a function of all TKA cases) in the United States has not decreased over time [3, 16, 17]. Understanding the causes of TKA failure and types of TKA procedures performed are essential to improving implant performance and longterm patient outcomes. We therefore: (1) identified the indications for revision TKA; (2) determined revision TKA procedure frequencies; (3) evaluated adoption and usage of the newly adopted ICD-9-CM diagnosis and procedure codes related to revision TKA; (4) assessed age, gender, race, payor type and US Census Region of revision TKA patients; and (5) ascertained length of stay and total charge by type of revision TKA procedure.

Our findings are limited by a relatively short time period of data collection, and uncertain compliance and accuracy of coding related to both the diagnosis/cause of failure and the type of revision procedure performed. However, the administrative codes used in this study are currently being used by governmental and nongovernmental public reporting agencies to compare failure rates and revision rates among surgeons and hospitals. Therefore, it is important for the surgeon community to be aware of strengths and limitations of this data, and the importance of detailed clinical documentation in order to improve the accuracy and clinical relevance of administrative codes related to TKA failure and revision TKA. Further study will be necessary to determine if our findings persist in larger data sets encompassing longer time periods.

Although our results represent only the early experience with the new ICD-9 diagnosis and procedure codes over a relatively short time period ( 15 months), the large number of procedures (over 60,000) included in our analysis provides unique and previously unavailable insight into the current causes of revision TKA procedures in a wide variety of care delivery settings throughout the entire United States. Since the existing literature contains limited information regarding the causes of TKA failure in large populations, it is difficult to compare our findings to those of previous investigators. Sharkey et al. [26] reported that polyethylene wear, aseptic loosening, and instability were the most common causes of revision TKA in a series of 203 consecutive revision TKAs performed over a 3-year period at a single institution. Other investigators [8, 18-20, 27] have implicated aseptic loosening, polyethylene wear, osteolysis, pain, stiffness, and instability as common causes of TKA failure. However, similar to the findings of Fehring et al. [6] and Vessely et al. [28], both of whom reported infection as a frequent mode of TKA failure, our data indicate that prosthetic joint infection is currently the most common indication for revision TKA in the United States. This is particularly concerning, especially given the substantial resources required to treat prosthetic joint infections, and the relatively poor patient outcomes that have been reported with both single- and two-stage revision TKA for infection compared with the results of revision TKA for aseptic causes of failure [1, 7, 13, 24, 29]. As the number of primary TKA procedures performed in the next two decades is expected to rise exponentially [14], increased resources should be devoted to research investigation and product development focused on prevention, early diagnosis, and treatment of prosthetic joint infection. 
The newly implemented ICD-9-CM diagnosis and procedure codes related to revision TKA provide valuable insight into the cause of failure and type of revision TKA procedure performed. Our analysis suggests that adoption of the new revision TKA-related ICD-9-CM procedure codes (by hospital administrative coding personnel) and diagnosis codes (by surgeons) is relatively high, but could be improved with additional education and training regarding the appropriate use of these new codes. Specifically, it appears that some of the codes may be ambiguous as currently defined, (eg, ICD-9 diagnosis code 996.43, "implant failure/ breakage"), which may be creating some confusion among both clinicians and coding personnel. Also, inadequate clinical documentation may have accounted for the relatively large percentage of cases $(15.4 \%)$ that were coded as "other mechanical complications." Furthermore, it is possible that certain isolated tibial liner exchange procedures are being incorrectly coded by hospital coding personnel as tibial component revisions, which could be artificially inflating the prevalence of tibial component revision procedures in administrative databases. The value of these new administrative diagnosis and procedure codes in terms of understanding the cause of TKA failure and monitoring trends in failure rates and specific types of revision procedures will be dependent on a clear understanding of the description and the intended meaning of each code, detailed and unambiguous clinical documentation, and appropriate use of the new codes when submitting administrative claims related to revision TKA procedures. The validity of the administrative claims data is expected to improve as surgeons and administrative coding personnel become more familiar with their definitions and appropriate usage.

Although useful information related to TKA failures can be derived from clinical case series and cohort studies, our study illustrates the value of large administrative databases in evaluating the epidemiology of revision TKA in a large population. However, although the newly implemented ICD-9-CM diagnosis and procedure codes reviewed in this study would provide valuable data elements for a U.S. Joint Replacement Registry, they should not be considered an acceptable substitute for a true TJR registry, as they lack essential information regarding the specific implants used in a procedure, and other important clinical and demographic information. As experience is gained with the new ICD-9-CM diagnosis and procedure codes related to revision TKA, valuable insight will be gained into TKA failure mechanisms, which may help guide future research, implant design, and clinical decision making related to total knee arthroplasty.

Acknowledgments We thank the Orthopaedic Research \& Education Foundation for this support of this work, and Erik Hansen, MD for his assistance in preparing this manuscript.
Open Access This article is distributed under the terms of the Creative Commons Attribution Noncommercial License which permits any noncommercial use, distribution, and reproduction in any medium, provided the original author(s) and source are credited.

\section{References}

1. Bengtson S, Knutson K. The infected knee arthroplasty. A 6-year follow-up of 357 cases. Acta Orthop Scand. 1991;62;301-311.

2. Berger RA, Rosenberg AG, Barden RM, Sheinkop MB, Jacobs JJ, Galante JO. Long-term followup of the Miller-Galante total knee replacement. Clin Orthop Relat Res. 2001;388:58-67.

3. Bourne RB, Maloney WJ, Wright JG. An AOA critical issue. The outcome of the outcomes movement. J Bone Joint Surg Am. 2004;86;633-640.

4. Bozic K. CMS changes ICD9 and DRG codes for revision TJA. AAOS Bulletin. 2005;3:17-21.

5. Emmerson KP, Moran CG, Pinder IM. Survivorship analysis of the Kinematic Stabilizer total knee replacement: a 10- to 14-year follow-up. J Bone Joint Surg Br. 1996;78;441-445.

6. Fehring TK, Odum S, Griffin WL, Mason JB, Nadaud M. Early failures in total knee arthroplasty. Clin Orthop Relat Res. 2001;392:315-318.

7. Goldman RT, Scuderi GR, Insall JN. Two-stage reimplantation for infected total knee replacement. Clin Orthop Relat Res. 1996;331:118-124.

8. Gonzalez MH, Mekhail AO. The failed total knee arthroplasty: evaluation and etiology. J Am Acad Orthop Surg. 2004;12;436446.

9. Heck DA, Melfi CA, Mamlin LA, Katz BP, Arthur DS, Dittus RS, Freund DA. Revision rates after knee replacement in the United States. Med Care. 1998;36;661-669.

10. Huang CH, Liau JJ, Lung CY, Lan CT, Cheng CK. The incidence of revision of the metal component of total knee arthroplasties in different tibial-insert designs. Knee. 2002;9;331-334.

11. Indelli PF, Aglietti P, Buzzi R, Baldini A. The Insall-Burstein II prosthesis: a 5- to 9-year follow-up study in osteoarthritic knees. J Arthroplasty. 2002;17;544-549.

12. Keating EM, Meding JB, Faris PM, Ritter MA. Long-term followup of nonmodular total knee replacements. Clin Orthop Relat Res. 2002;404:34-39.

13. Kramhoft M, Bodtker S, Carlsen A. Outcome of infected total knee arthroplasty. J Arthroplasty. 1994;9;617-621.

14. Kurtz S, Ong K, Lau E, Mowat F, Halpern M. Projections of primary and revision hip and knee arthroplasty in the United States from 2005 to 2030. J Bone Joint Surg Am. 2007;89;780785 .

15. Mahomed NN, Barrett J, Katz JN, Baron JA, Wright J, Losina E. Epidemiology of total knee replacement in the United States Medicare population. J Bone Joint Surg Am. 2005;87;12221228.

16. Maloney WJ. National Joint Replacement Registries: has the time come? J Bone Joint Surg Am. 2001;83;1582-1585.

17. Maloney WJ. An American implant registry: a clinical use trip wire. Orthopedics. 2002;25;923-924.

18. Mikulak SA, Mahoney OM, dela Rosa MA, Schmalzried TP. Loosening and osteolysis with the press-fit condylar posteriorcruciate-substituting total knee replacement. J Bone Joint Surg Am. 2001;83;398-403.

19. Mulhall KJ, Ghomrawi HM, Scully S, Callaghan JJ, Saleh KJ. Current etiologies and modes of failure in total knee arthroplasty revision. Clin Orthop Relat Res. 2006;446;45-50. 
20. Peters, PC Jr, Engh GA, Dwyer KA, Vinh TN. Osteolysis after total knee arthroplasty without cement. J Bone Joint Surg Am. 1992;74;864-876.

21. Quintana JM, Arostegui I, Escobar A, Azkarate J, Goenaga JI, Lafuente I. Prevalence of knee and hip osteoarthritis and the appropriateness of joint replacement in an older population. Arch Intern Med. 2008;168;1576-1584.

22. Rorabeck CH, Murray P. Cost effectiveness of revision total knee replacement. Instr Course Lect. 1997;46;237-240.

23. Saleh KJ, Santos ER, Ghomrawi HM, Parvizi J, Mulhall KJ. Socioeconomic issues and demographics of total knee arthroplasty revision. Clin Orthop Relat Res. 2006;446;15-21.

24. Segawa H, Tsukayama DT, Kyle RF, Becker DA, Gustilo RB. Infection after total knee arthroplasty. A retrospective study of the treatment of eighty-one infections. J Bone Joint Surg Am. 1999;81;1434-1445.
25. Sextro GS, Berry DJ, Rand JA. Total knee arthroplasty using cruciate-retaining kinematic condylar prosthesis. Clin Orthop Relat Res. 2001;388:33-40.

26. Sharkey PF, Hozack WJ, Rothman RH, Shastri S, Jacoby SM. Insall Award paper. Why are total knee arthroplasties failing today? Clin Orthop Relat Res. 2002;404:7-13.

27. Sheng P, Lehto M, Kataja M, Halonen P, Moilanen T, Pajamaki J. Patient outcome following revision total knee arthroplasty: a meta-analysis. Int Orthop. 2004;28;78-81.

28. Vessely MB, Whaley AL, Harmsen WS, Schleck CD, Berry DJ. The Chitranjan Ranawat Award: Long-term survivorship and failure modes of 1000 cemented condylar total knee arthroplasties. Clin Orthop Relat Res. 2006;452;28-34.

29. Wilde AH, Ruth JT. Two-stage reimplantation in infected total knee arthroplasty. Clin Orthop Relat Res. 1988;236: $23-35$. 